\title{
PENERAPAN INTERNET OF THINGS (IoT) PADA SISTEM MONITORING IRIGASI (SMART IRIGASI)
}

\author{
David Setiadi ${ }^{1)}$, Muhamad Nurdin Abdul Muhaemin ${ }^{2)}$ \\ Prodi. Teknik Informatika ${ }^{1)}$ 2) \\ STMIK Sumedang ${ }^{1)}$, Universitas Sangga Buana YPKP ${ }^{2)}$ \\ davidsetiadi1@gmail.com ${ }^{1)}$, noordiens89@gmail.com ${ }^{2)}$
}

\begin{abstract}
ABSTRAK
Irigasi adalah suatu upaya untuk pengelolaan dan penyediaan air untuk menunjang kebutuhan pertanian. Irigasi membutuhkan biaya yang besar baik untuk pengadaan sarana, prasarana, pengelolaan dan proses pemeliharaan. Pengaturan dengan cara yang tepat adalah suatu kebutuhan agar pengelolaan air irigasi dapat dimanfaatkan secara maksimal. Volume air yang digunakan dipengaruhi beberapa faktor, baik dari keadaan alam juga berkembangnya kegiatan manusia. Pada pelaksanaannya sering terjadi debit air yang mengaliri saluran irigasi mengalami pasang surut pada waktu yang tidak bisa ditentukan sehingga diperlukan sistem yang mampu mengatur buka tutup pintu dari bendungan supaya air terawasi dengan baik. Untuk saat ini sistem buka tutup pintu bendungan irigasi dilakukan secara manual oleh manusia, sehingga harus ada petugas yang siaga agar debit air tidak meluap. Smart Irigasi merupakan sebuah rancangan teknologi masa kini yang memungkinkan dapat menjadikan solusi praktis untuk melakukan monitoring dan kontroling terhadap sistem saluran irigasi, sensor-sensor yang terintegrasi akan mengirimkan data untuk melakukan monitoring melalui jaringan internet pada lingkungan sistem irigasi meliputi suhu,cuaca, debit air yang mengalir serta ketinggian air pada saluran sistem irigasi, dan juga dapat melakukan kontroling sistem buka tutup pintu bendungan secara otomatis disertai dengan ada nya pemberitahuan baik melalui website ataupun SMS jika sewaktuwaktu air meluap. Sehingga dengan adanya Smart Irigasi diharapkan mampu meringankan beban kerja manusia dalam melakukan monitoring dan kontroling pada suatu sistem aliran irigasi.
\end{abstract}

Kata kunci : IoT, Sistem Monitoring, Irigasi

\section{PENDAHULUAN}

Indonesia sebagai negara agraris yang memiliki sumberdaya alam melimpah yang dijadikan sebagai sumber penghasilan dan sumber makanan. Kebutuhan air begitu vital terutama untuk memenuhi kebutuhan kelestarian tumbuhan atau lahan pertanian. Perlu diterapkan pengaturan untuk mengontrol sistem saluran irigasi yang bisa mengoptimalkan pemanfaatan pasokan air.

Mempertimbangkan pasokan air yang tersedia sering tidak memenuhi kebutuhan baik dari faktor lokasi maupun waktunya, maka dibutuhkan saluran dan bangunan pelengkap (seperti : bendungan, siphon, pompa air, gorong-gorong, talang air dan lainnya) untuk mengalirkan air dari sumbernya ke tempat yang dituju juga sekaligus untuk mengontrol debit air yang dialirkan maupun yang dibutuhkan.
Pada pelaksanaan nya sering terjadi debit air yang mengaliri saluran irigasi mengalami pasang surut pada waktu yang tidak bisa ditentukan sehingga dibutuhkan adanya pengaturan sistem buka tutup pintu air di bendungan supaya air tidak melebihi kapasitas bendungan. Untuk saat ini sistem buka tutup pintu bendungan irigasi dilakukan secara manual oleh manusia, sehingga harus ada petugas yang siaga agar debit air tidak meluap.

Di era kemajuan teknologi ini, bukan hal yang tidak mungkin untuk menciptakan sebuah inovasi baru, membuat sistem "pintar" yang dapat mengontrol buka tutup pintu bendungan secara otomatis, salah satunya dengan membangun sistem "Smart irigasi" dengan mengimplementasikan konsep internet of things dimana konsep ini dapat menghubungkan benda-benda dengan koneksi internet sehingga dapat dilakukan pemantauan,pengontrolan melalui jaringan internet. 
Smart irigasi akan dibangun guna mengontrol dan memonitoring aktivitas saluran irigasi seperti, memantau debit air, suhu udara, ketinggian air , deteksi hujan dan sistem otomatisasi buka tutup pintu bendungan , sehingga diharapkan pasokan air dari saluran irigasi dapat lebih optimal juga meringankan pekerjaan manusia karena dengan sistem smart irigasi, aktivitas dapat di pantau dari jarak jaug baik menggunakan smartphone, personal komputer, maupun laptop.

\section{TINJAUAN PUSTAKA}

\section{Pengertian Irigasi}

Menurut Linsley dan Franzini (1992) irigasi adalah pengaliran air pada tanah untuk membantu pengaturan ketersedian air dikarenakan curah hujan yang tidak cukup sehingga air bisa tersedia secara optimal bagi pertumbuhan tanaman.

Sedangkan defini irigasi menurut Hansen (1990) merupakan penggunaan air tanah untuk penyediaan air yang diperlukan untuk pertumbuhan tanaman.

Dalam dokumen Peraturan Pemerintah No. 23/1982 Pasal 1, irigasi, bangunan dan petak irigasi yang telah dibakukan yaitu :

a. Irigasi adalah usaha penyediaan dan penyediaan dan pengaturan air untuk menunjang pertanian.

b. Jaringan irigasi adalah saluran dan bangunan yang merupakan satu kesatuan dan diperlukan untuk pengaturan air irigasi mulai dari penyediaan, pengambilan, pembagian pemberian dan penggunaannya.

c. Daerah irigasi adalah kesatuan wilayah yang mendapat air dari satu jaringan irigasi.

d. Petak irigasi adalah petak tanah yang memperoleh air irigasi. berikut:

Jenis-jenis Irigasi diantaranya sebagai

Seperti yang telah dijelaskan diatas irigasi adalah suatu tindakan memindahkan air dari sumbernya ke lahan-lahan pertanian, adapun pemberiannya dapat dilakukan secara gravitasi atau dengan bantuan pompa air. Pada implementasinya ada empat jenis irigasi dilihat dari cara penyalurannya :
a. Irigasi gravitasi
b. Irigasi bawah tanah
c. Irigasi siraman
d. Irigasi tetesan

\section{Internet of things}

Menurut Coordinator and support action for global RFID-related activities and standadisation menyatakan internet of things (IoT) sebagai sebuah infrastruktur koneksi jaringan global, yang mengkoneksikan benda fisik dan virtual melalui eksploitasi data capture dan teknologi komunikasi. Infrastruktur IoT terdiri dari jaringan yang telah ada dan internet berikut pengembangannya. Hal ini menawarkan identifikasi obyek, identifikasi sensor dan kemampuan koneksi yang menjadi dasar untuk pengembangan layanan dan aplikasi koperatif yang berdiri secara independen, juga ditandai dengan tingkat otonomi data capture yang tinggi, event transfer, konektivitas pada jaringan dan juga interoperabilitas.

Menurut IEEE(Institute of Electrical and Electronics Engineers) Internet of things (IoT) didefinisikan sebagai sebuah jaringan dengan masing-masing benda yang ternanam dengan sensor yang terhubung kedalam jaringan internet. (IEEE “Internet of things" 2014)

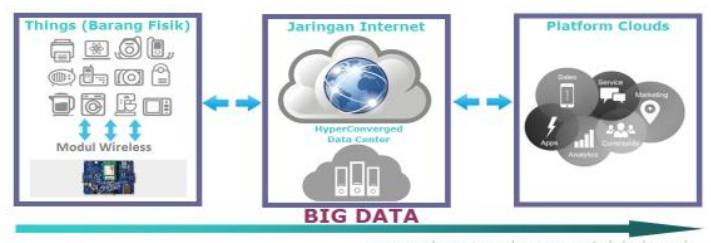

Gambar 1. konsep internet of things

Konsep internet of things mencangkup 3 elemen utama yaitu: benda fisik atau nyata yang telah diintegrasikan pada modul sensor, koneksi internet, dan pusat data pada server untuk menyimpan data ataupun informasi dari aplikasi. Penggunaan benda yang terkoneksi ke internet akan menghimpun data yang kemudian terkumpul menjadi 'big data' untuk kemudian diolah, dianalisa baik oleh instansi pemerintah, perusahaan terkait, maupun instansi lain kemudian di manfaatkan bagi kepentingan masing-masing.

\section{Mikrokontroller}

Menurut Fauzi(2011) mikrokontroler merupakan sebuah chip yang bertugas sebagai pengatur rangkaian elektronika dan umumnya dapat ditanamkan program didalamnya.

Berdasarkan definisi tersebut bisa dinyatakan bahwa mikrokontroller merupakan 
suatu integrated circuit yang dirancang dengan kepadatan tinggi, dimana bagian yang dibutuhkan suatu mikrokontroler sudah dibuat menjadi kepingan, biasanya mencangkup CPU (Central Processing Unit), EEPROM/EPROM/PROM/ROM, RAM (Random Access Memory), Parallel \& Serial, Timer dan Interupt Controller yang berfungsi sebagai pengatur rangkaian elektronik serta secara umum dapat ditanamkan program di dalamnya.

Menurut Setiawan (2011) mikrokontroler merupakan perangkat yang bertugas melakukan perintah-perintah yang diberikan kepadanya. Mikrokontroler menjadi bagian utama dari suatu program terkomputerisasi.

Program tersebut memberikan perintah pada komputer untuk mengerjakan hubungan yang panjang dari fungsi-fungsi tertentu untuk melaksanakan tugas yang komplek yang dibuat oleh pemrogram. (2011:10)

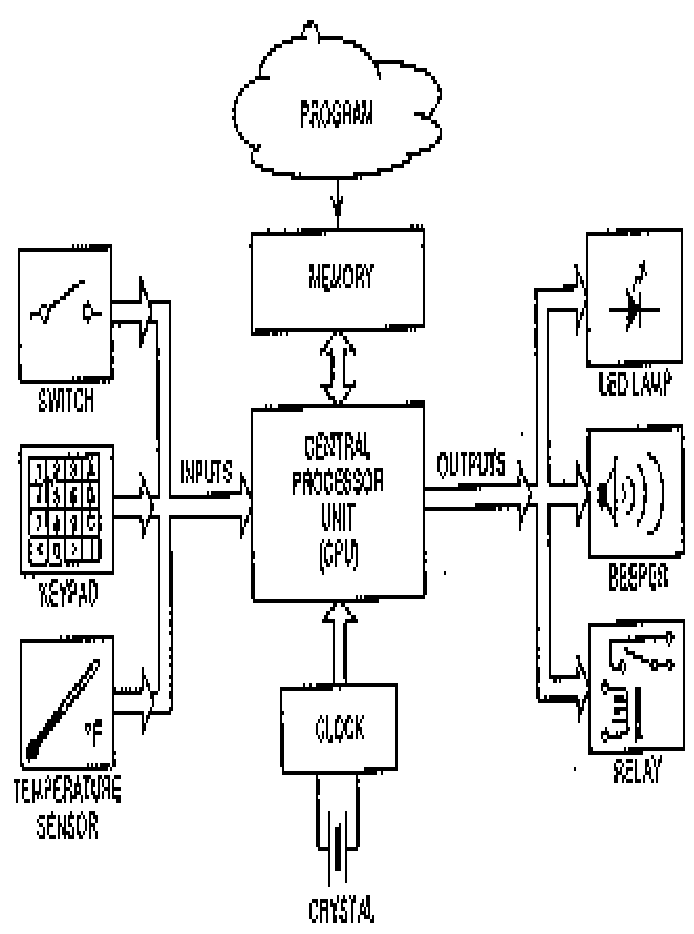

Gambar 2. Blok Mikrokontroller

\section{Wemos D1 mini}

Wemos D1 mini merupakan sebuah perangkat modul wifi berbasis mikrokontroller ESP-8266 , wemos d1 mini memiliki fungsi yang tidak jauh berbeda dengan arduino yang fungsinya sebagai alat pengedali mikro yang bersifat open source, perangkat ini dapat dipakai dalam pengembangan proyek internet of things. Wemos d1 mini dapat di program dengan menggunakan software Arduino IDE.

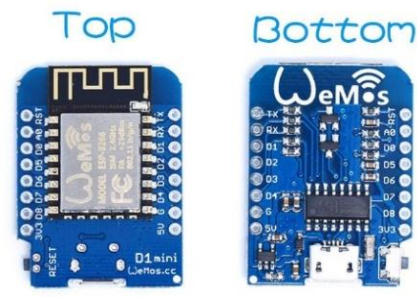

Gambar 3. Wemos D1 mini

\section{METODOLOGI}

Metodologi yang akan digunakan dalam penelitian ini untuk membangun sistem Smart irigasi adalah dengan menggunakan model SDLC (System Development Life Cycle) waterfall, dimana uraian tahapan pengembangan dari model waterfall dimulai dari tahapan analisis sistem, desain sistem dan seterusnya hingga tahapan pemeliharaan sistem, siklus dari model waterfall dapat dilihat pada gambar 4.

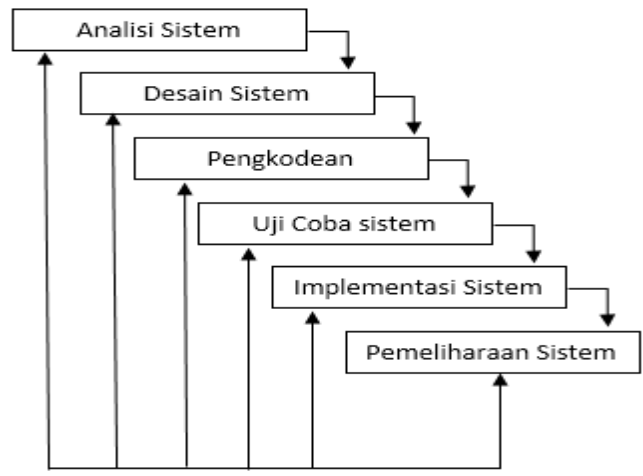

Gambar 4. Skematik model SDLC waterfall

1. Analisis Sistem

Pada tahapan analisis sistem, penulis menganalisis permasalahan yang terjadi dengan cara melakukan observasi pada sistem saluran irigasi untuk dapat melihat cara kerja, proses serta masalah yang terjadi pada sistem saluran irigasi tersebut.

\section{Desain Sistem}

Pada tahapan ini desain sistem dilakukan untuk merancang sistem sesuai dengan kebutuhankebutuhan sistem yang akan dibangun untuk menjadikan solusi bagi permasalahan yang ada, penulis membuat rancangan sistem dan 
membuat skema cara kerja sistem kedalam bentuk diagram guna memberikan gambaran mengenai alur sistem yang dibuat, serta membuat skematik rangkaian alat atau blok diagram dari rangkaian alat yang akan digunakan untuk membangun sistem smart irigasi dengan menggunakan aplikasi Fritzing. Selain itu penulis membuat sketsa interface tampilan website yang antinya akan digunakan sebagai media untuk memonitor aktivitas saluran irigasi menggunakan aplikasi pengolah gambar Corel draw X3.

\section{Pengkodean Program}

Tahapan pengkodean merupakan tahapan untuk menterjemahkan hasil dari desain sistem yang telah dibuat kedalam sebuah bahasa program yang dapat di proses oleh sebuah komputer, pada tahapan ini penulis membuat kode program untuk memprogram mikrokontroller sebagai sebagai pengontrol dari sensor-sensor yang akan digunakan dalam sistem Smart irigasi. Mikrokontroller yang digunakan adalah wemos D1 mini yang sudah terintergrasi mikrokontroller ESP-8266, penulis menggunakan software arduino IDE untuk memprogram wemos D1 mini agar dapat mentransmisikan data hasil dari hasil inputan oleh sensor-sensor yang digunakan.

\section{Uji Coba Sistem}

Pada tahapan uji coba sistem, penulis melakukan uji coba sistem dengan metode black-box testing dimana pengujian ini berfokus pada spesifikasi fungsional dari perangkat lunak.

Pengujian black-box memuat petunjuk untuk menguji program sehingga menghasilkan program yang valid secara $100 \%$ dan digunakan untuk mengetahui keberhasilan dari program yang telah dibangun.

\section{Implementasi sistem}

Tahapan ini merupakan tahapan untuk menerapkan sistem yang telah siap untuk digunakan dan telah melewati masa uji coba sistem, langkah-langkah dalam implementasi sistem sebagai berikut:
a. Menyiapkan perangkat
Mempersiapkan perangkat sistem Smart irigasi yang telah di rancang dan dibangun dengan mengintegrasikan beberapa sensor.
b. Melakukan simulasi

Sistem Smart irigasi dirancang dan dibangun dalam bentuk maket/prototipe sehinggan perlu dilakukan simulasi untuk melihat cara kerja dari sistem Smart irigasi.

\section{Pemeliharaan sistem}

Pemeliharan sistem dilakukan agar sistem dapat terus bekerja dengan baik, terutama pada sensor-sensor yang digunakan perlu dilakukan kalibrasi secara rutin agar mendapatkan hasil pengukuran serta inputan untuk memonitoring secara presisi. Serta melakukan pengontrolan terhadap mikrokontroller untuk memastikan perangkat terus bekerja dengan baik dan benar.

\section{HASIL DAN PEMBAHASAN}

Smart irigasi merupakan sebuah rancangan berbentuk prototype, sebagai inovasi dalam pengembangan sistem irigasi yang di desain untuk meringankan beban kerja manusia serta meningkatkan aktivitas kontroling terhadap lingkungan irigasi.

\section{A. Rangkaian skematik perangkat Smart Irigasi}

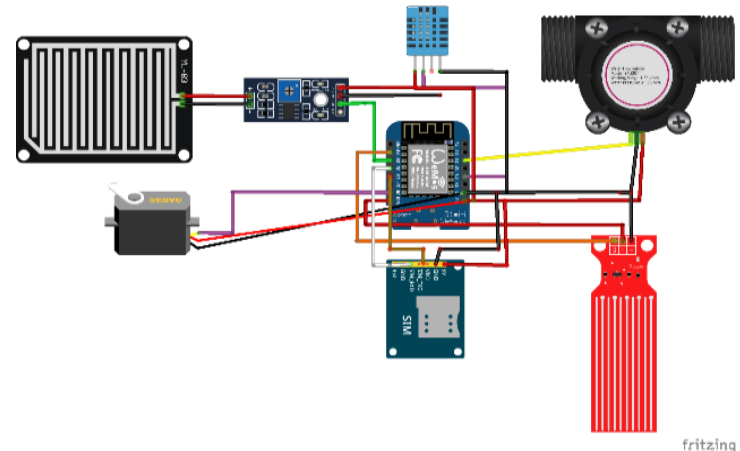

Gambar 5. Rangkaian Skematik Perangkat Smart Irigasi

Perangkat Smart Irigasi terdiri dari 4 sensor yang terhubung pada mikrokontroller Wemos D1 mini diantaranya, sensor waterflow yang berfungsi sebagai sensor untuk menghitung debit air yang mengalir pada sistem irigasi, kedua sensor suhu yang berfungsi mendeteksi suhu sekitar, ketiga sensor hujang yang berfungsi sebagai pendeteksi cuaca , kemudian sensor water level untuk mendeteksi ketinggian air dari sistem saluran irigasi.

Kemudian pada perangkat Smart Irigasi dibenamkan servo dan modul gsm sebagai alat kontroling sistem irigasi, servo berfungsi 
sebagai motor penggerak untuk menutup-buka pintu bendungan sesuai ketinggian air secara otomatis, dan modul gsm berfungsi untuk mengirimkan pemberitahuan melalui sms jika air pada saluran irigasi sedang meluap.

\section{B. Monitoring sistem irigasi}

Smart Irigasi memungkinkan untuk melakukan kontroling dan monitoring sistem irigasi jarak jauh, sensor-sensor yang terpasang pada sistem irigasi terkoneksi dengan jaringan internet. Data dari sensor akan dikirimkan melalui jaringan internet secara real-time.

User dapat melakukan aktivitas kontroling dan monitoring dengan membuka alamat website yang telah dibuat untuk menampilkan data-data dari sensor yang ada pada sistem Smart Irigasi.

Untuk mengakses server/website pada sistem Smart Irigasi user dapat menggunakan personal komputer/laptop atau dengan menggunakan smartphone

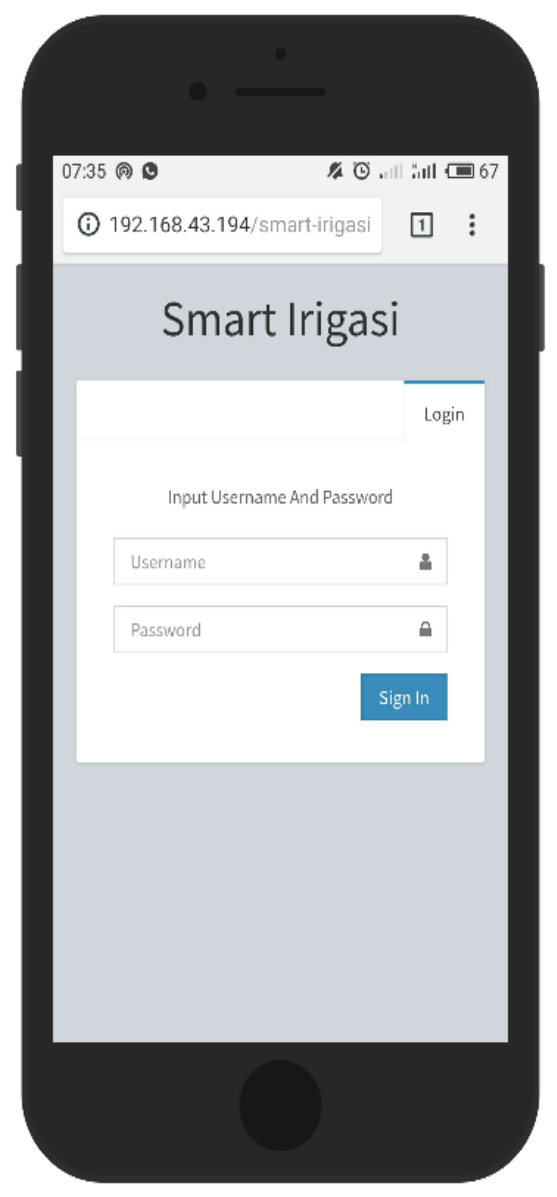

Gambar 5. Antarmuka Login Smart Irigasi
Antarmuka gambar 5 merupakan tampilan pertama pada saat mengakses Smart Irigasi, demi keamanan sistem, setiap user yang akan mengakses diwajibkan memiliki username dan kata sandi yang telah terdaftar pada sistem Smart Irigasi.

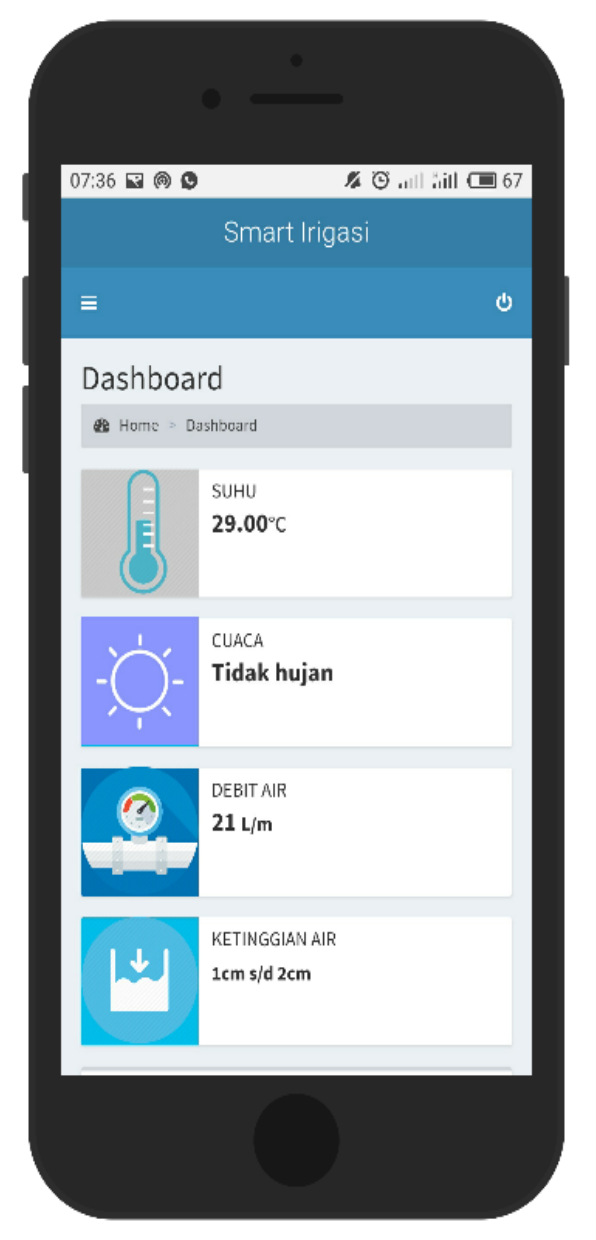

\section{Gambar 6. Tampilan Dashboard Smart Irigasi}

Setelah user berhasil login. User akan di arahkan ke halaman dashboard, pada halaman dashboard terdapan beberapa panel-panel yang menyajikan data dari sensor-sensor yang berada pada sistem Smart Irigasi.

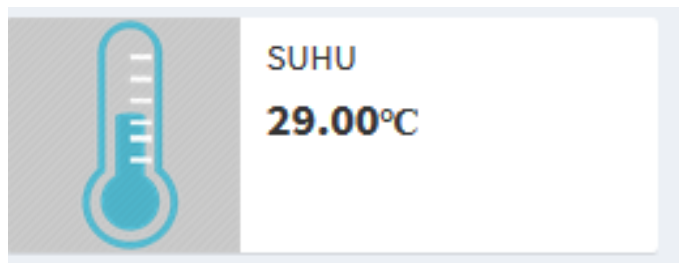

Gambar 7. Panel Sensor Suhu 
Panel pertama menampilkan data suhu saat ini (realtime) di kawasan sistem irigasi, data suhu akan berubah-ubah sesuai suhu yang ada pada wilayah irigasi. Data suhu ditangkap sesuai dengan suhu sekitar menggunakan sensor dht11 lalu ditransmisi kan oleh mikrokontroller melalui jaringan internet sehingga hasil nya akan tampil di server/web.

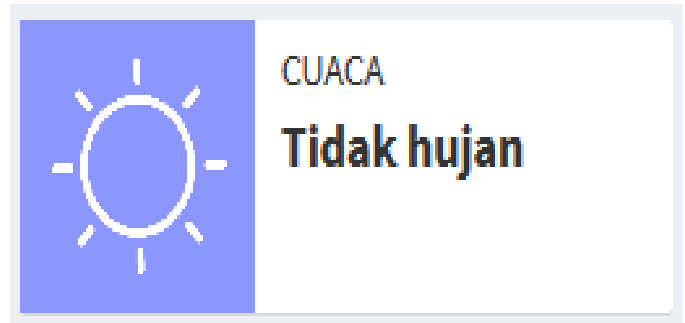

Gambar 8. Panel Cuaca

Panel kedua menampilkan status cuaca saat ini, data yang ditampilkan menggunakan sensor raindrop, jika pada sensor terdeteksi air, maka sensor akan mengirimkan data dengan status hujan, gambar icon pada panel akan berubah menjadi awan hujan seperti pada gambar di bawah.

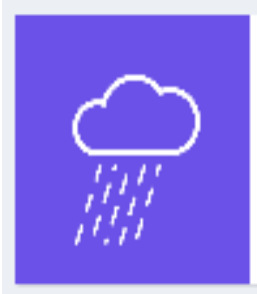

\section{CUACA \\ Hujan}

Gambar 9. Panel Cuaca Hujan

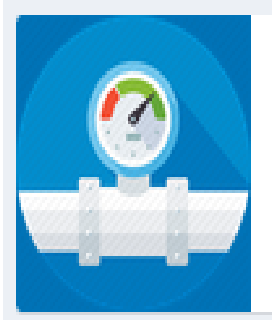

\section{DEBIT AIR}

\section{$21 \mathrm{~L} / \mathrm{m}$}

Gambar 10. Panel Debit Air

Panel ketiga menampilkan debit air yang mengalir pada sistem irigasi, sensor yang di gunakan adalah Water Flow Sensor tipe, Sensor tipe ini memiliki rotor dan transducer hall-effect didalamnya untuk mendeteksi putaran rotor ketika air melewatinya. Putaran tersebut akan menghasilkan pulsa digital yang banyaknya sebanding dengan banyaknya air yang mengalir melewatinya. Jumlah pulsa digital yang dibaca di konversikan kedalam satuan liter per menit.

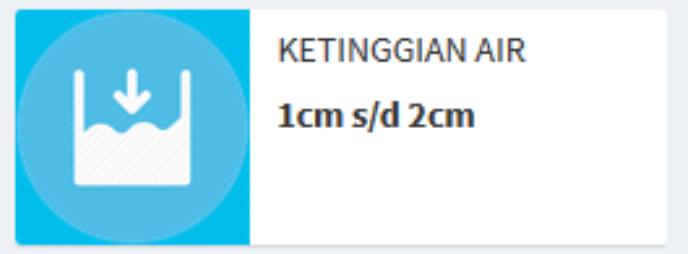

Gambar 11. Panel Ketinggian Air

Panel ke-empat menampilkan tinggi air , sensor yang digunakan yaitu Water Level Sensor dengan level $0 \mathrm{~s} / \mathrm{d} 4 \mathrm{~cm}$. sensor di celupkan kedalam bejana yang berisi air, ketika air berada pada permukaan sensor nilai masukan berupa analog yang di konversikan kedalam satuan centimetre $(\mathrm{cm})$.
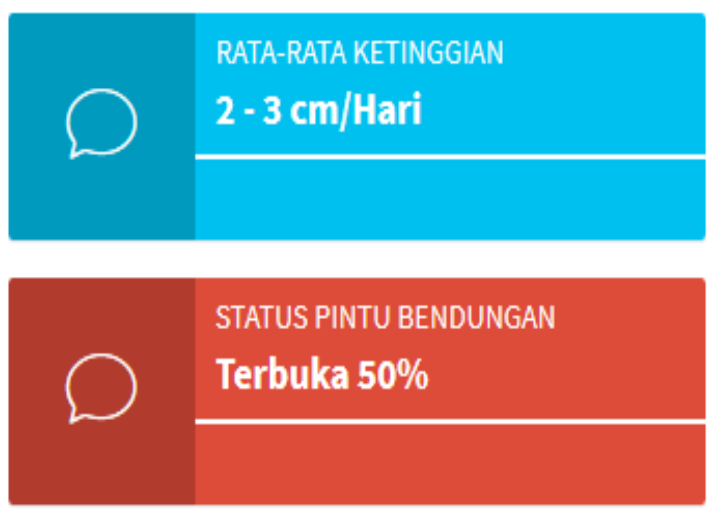

Gambar 12. Panel Status Smart Irigasi

Pada panel 12 menampilkan status ratarata ketinggian air dan bukaan pintu bendungan, lebar kecil nya bukaan pada pintu bendungan bersifat dinamis, pintu bendungan digerakan oleh servo secara otomatis mengikuti ketinggian air, jika level air sedang tinggi atau dalam artian meluap maka servo akan menggerakan pintu bendungan menutup penuh secara otomatis, disertai dengan adanya pemberitahuan berupa alarm berbunyi dan pada panel status pintu bendungan menunjukan teks berkedip.

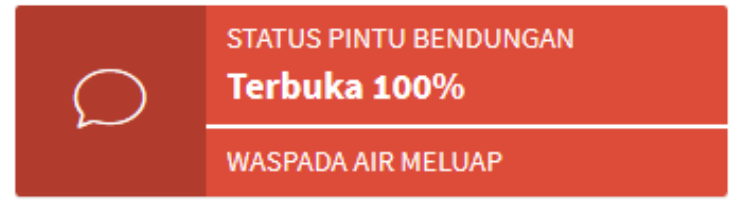

Gambar 13. Notifikasi Air Meluap 
Selain pemberitahuan yang ditampilkan pada web, perangkat Smart Irigasi juga akan mengirimkan SMS jika ketinggian air terdeteksi sedang tinggi/meluap.

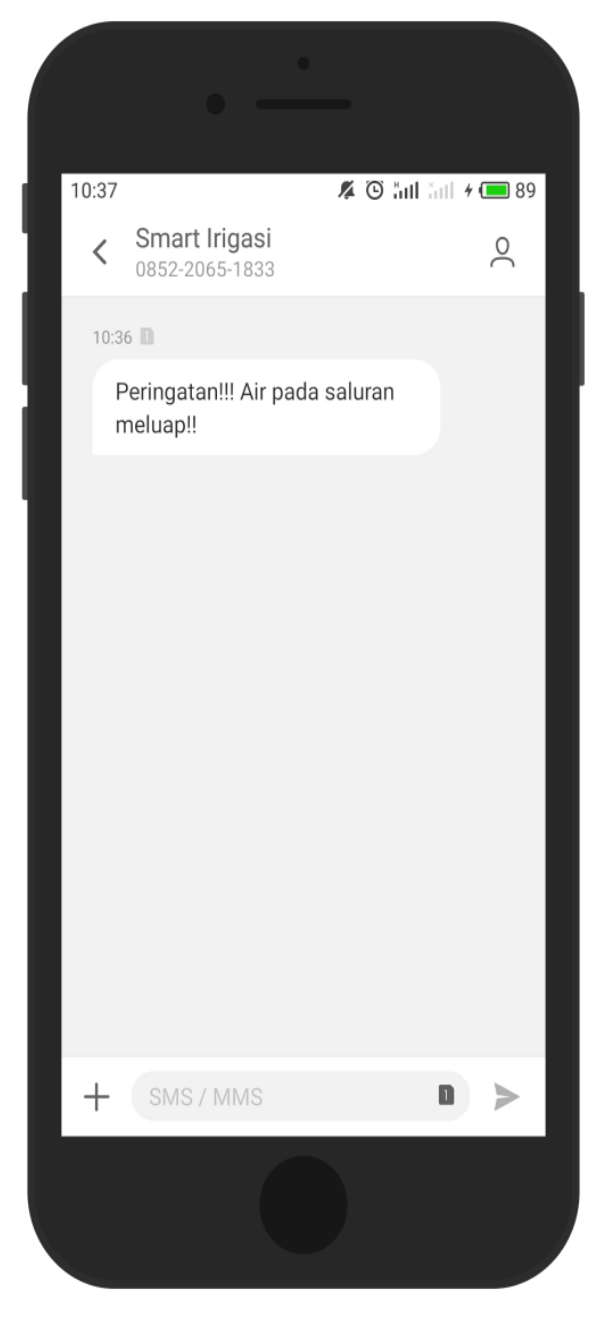

Gambar 14. SMS pemberitahuan

Mekanisme pengiriman SMS dilakukan ketika sensor water level mendeteksi level air tertinggi kemudian mikrokontroller akan mengirimkan SMS kepada nomor yang telah ditentukan, pesan yang akan diterima seperti pada gambar 14 .

Pada saat simulasi penentuan lebar buka tutup pintu bendungan seperti tabel di bawah:

Tabel 1. Simulasi penentuan lebar buka tutup pintu bendungan

\begin{tabular}{|c|c|}
\hline Ketinggiaan air & Bukaan Pintu \\
\hline $0-1 \mathrm{~cm}$ & Tertutup 100\% \\
\hline
\end{tabular}

\begin{tabular}{|c|c|}
\hline $1-2 \mathrm{~cm}$ & Terbuka $25 \%$ \\
\hline $2-3 \mathrm{~cm}$ & Terbuka $50 \%$ \\
\hline $3-4 \mathrm{~cm}$ & Terbuka $75 \%$ \\
\hline$>4 \mathrm{~cm}$ & Terbuka $100 \%$ \\
\hline
\end{tabular}

Ketentuan buka tutup pintu bendungan dapat disesuaikan sesuai dengan kondisi atau aturan buka tutup pintu bendungan sistem irigasi yang diterapkan pada suatu lokasi.

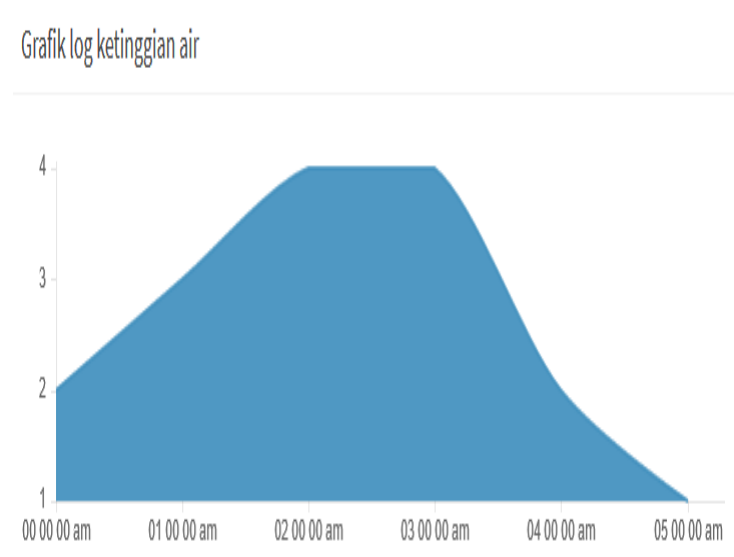

Gambar 15. Grafik Log Ketinggian Air

Pada gambar 15. menampilkan log ketinggian air setiap jam pada hari berjalan (hari ini), log ditampilkan dalam panel grafik. Data ketinggian air di catat setiap satu jam sekali sebagai bahan evaluasi untuk monitoring ketinggian air.

\section{C.Hasil Simulasi Smart Irigasi}

Tabel 2. Hasil Simulasi Irigasi

\begin{tabular}{|l|ll|}
\hline \multicolumn{1}{|c|}{ Kelas } & \multicolumn{2}{|c|}{ Validasi } \\
\hline $\begin{array}{l}\text { Mengiri } \\
\text { m data } \\
\text { suhu }\end{array}$ & $\begin{array}{l}\text { Data suhu dapat ditransmisikan } \\
\text { melalui jaringan internet dan } \\
\text { ditampilkan pada server/web Smart } \\
\text { lirigasi }\end{array}$ \\
\hline $\begin{array}{l}\text { Mendet } \\
\text { eksi } \\
\text { status } \\
\text { cuaca }\end{array}$ & $\begin{array}{l}\text { Data dari sensor raindrop berhasil } \\
\text { dibaca oleh mikrokontroller } \\
\text { kemudian data ditransmisikan } \\
\text { melalui jaringan internet dan } \\
\text { ditampilkan pada server/web Smart } \\
\text { lirigasi }\end{array}$ \\
\hline
\end{tabular}




\begin{tabular}{|l|l|}
\hline \multicolumn{1}{|c|}{$\begin{array}{c}\text { Kelas } \\
\text { uji }\end{array}$} & \multicolumn{2}{|c|}{ Validasi } \\
\hline $\begin{array}{l}\text { Memba } \\
\text { ca debit } \\
\text { air }\end{array}$ & $\begin{array}{l}\text { Air yang mengalir melewati sensor } \\
\text { Water flow dibaca sebagai nilai } \\
\text { pulsa digital dan di konversikan } \\
\text { kedalam satuan liter oleh } \\
\text { mikrokontroller } \\
\text { ditransmisikan melalui jaringan } \\
\text { internet dan ditampilkan pada } \\
\text { server/web Smart lirigasi }\end{array}$ \\
\hline $\begin{array}{l}\text { Mendet } \\
\text { eksi } \\
\text { Ketingg } \\
\text { ian air }\end{array}$ & $\begin{array}{l}\text { Ketinggian air di baca oleh sensor } \\
\text { water level kemudian data di olah } \\
\text { menggunakan mikro controller } \\
\text { sebagai acuan buka tutup otomatis } \\
\text { oleh servo serta data ketinggian air } \\
\text { ditampilkan pada server/web Smart } \\
\text { lirigasi }\end{array}$ \\
\hline
\end{tabular}

\section{KESIMPULAN}

Dari hasil pembahasan yang dilakukan pada penelitian yang berjudul "Penerapan Iot (Internet Of Things) Pada Sistem Monitoring Irigasi (Smart Irigasi)" maka dapat diambil kesimpulan bahwa dengan implementasi konsep internet of things (IoT) pada sistem irigasi menghasilkan sebuah perangkat yang dapat membantu melakukan aktivitas kontroling dan monitoring sistem irigasi jarak jauh, juga meringankan beban kerja manusia dalam mengatur buka tutup pintu bendungan yang semulanya dilakukan secara manual oleh tenaga manusia dengan sistem Smart Irigasi buka tutup pintu bendungan irigasi dilakukan secara otomatis sesuai dengan ketinggian air yang telah ditentukan.

\section{DAFTAR PUSTAKA}

[1] GSM Association. 2014. Understanding the internet of things (IoT).

[2] Minerva, Roberto.,dkk. 2015. Towards a definition of the Internet of Things (IoT).

[3] Vermesan, Ovidiu. \& Friess, Peter. 2014. Internet of Things - From Research and Innovation to Market Deployment. Denmark: River Publisher.

[4] Cindy, 2015. Pengertian dan Perbedaan Sinyal Analog dan juga Digital, diakses 18 April 2017, dari http://www.saggaus.net/2015/08/pengertian-dan-perbedaansinyal-analog.html.

[5] Naziq, Ahmad, 2017. Pengertian Mikrokontroler, diakses pada 20 April 2017 , https://sites.google.com/site/informasit Erbarusekali / pengertian-mikrokontro 